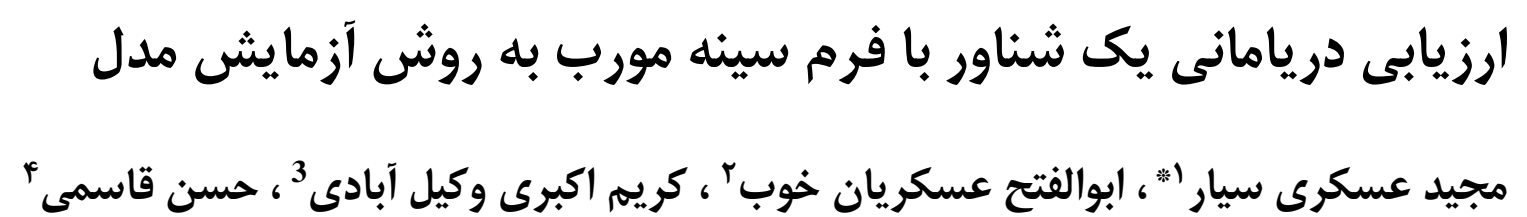

ا كارشناسى ارشد هيدرومكانيك، دانشعاه علوم دريايى امام خمينى(ره)- نوشهر، gmail.com r استاديار دانشكده مهندسى مكانيك، دانشگاه علوم دريايى امام خمينى(ره)- نوشهر، gmail.com

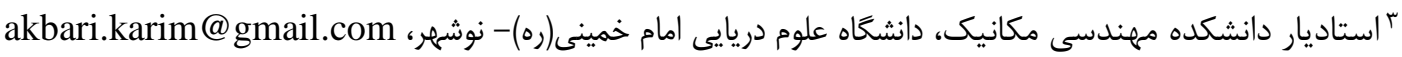

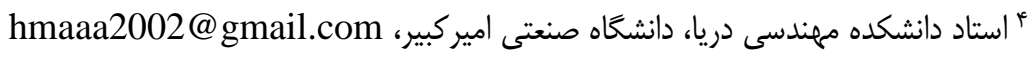

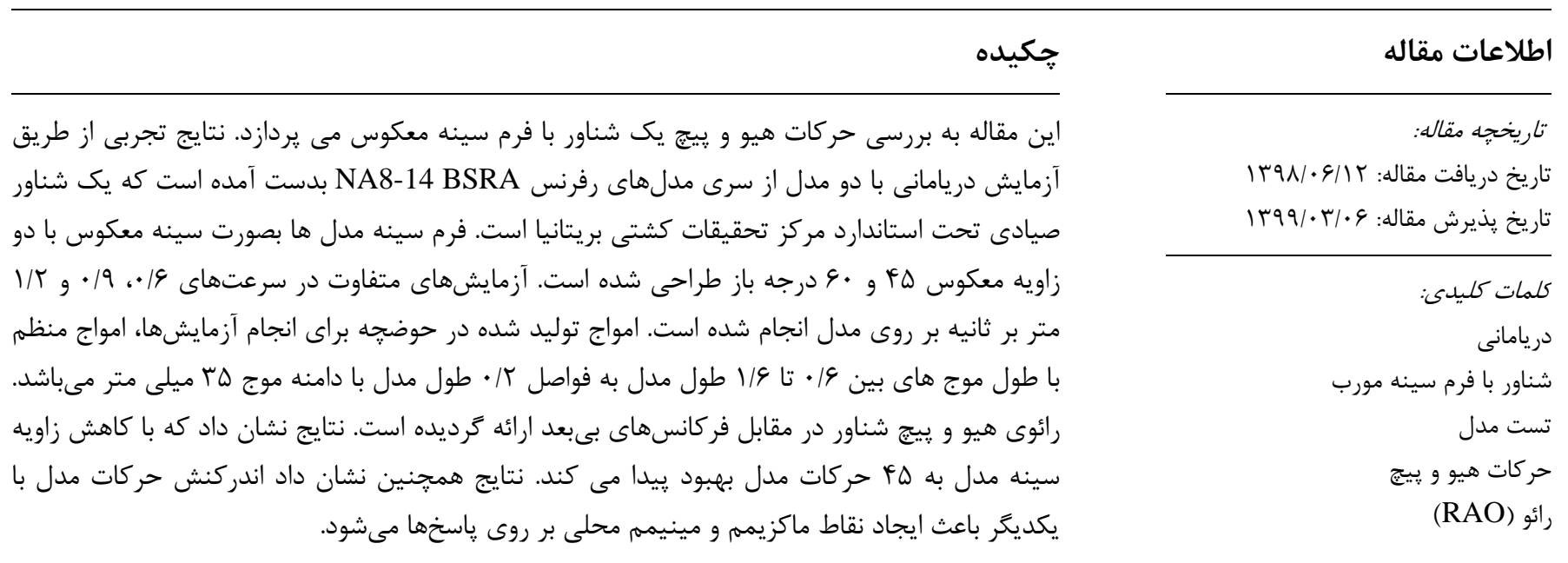

\title{
The Seakeeping Investigation of an Inverted Bow Hull by Experimental Method
}

\section{Majid Askary Sayar ${ }^{1 *}$, Abolfath Askarian Khoob ${ }^{2}$, Karim Akbari Vakilabadi ${ }^{3}$, Hassan Ghassemi $^{4}$}

${ }^{1}$ Ms., Marine Faculty of Imam Khomeini Maritime University, Nowshahr; majidaskary1363@gmail.com

${ }^{2}$ Assistant Professor, Marine Faculty of Imam Khomeini Maritime University, Nowshahr; askariankhoob@gmail.com

${ }^{3}$ Assistant Professor, Marine Faculty of Imam Khomeini Maritime University, Nowshahr; akbari. karim@gmail.com

${ }^{4}$ Professor, Department of Marine Technology, Amirkabir University of Technology; hmaaa2002@gmail.com

\section{ARTICLE INFO}

Article History:

Received: 03 Sep. 2019

Accepted: 26 May. 2020

\section{Keywords:}

Seakeeping

Inverted bow hull

Model test

Heave and Pitch motions

RAO

\begin{abstract}
This paper investigates the heave and pitch motion responses of an inverted bow hull. The experimental data were obtained from seakeeping tests with two scaled models of reference fishing vessel NA8-14 BSRA. The bow shape of the models is redesigned by inverted shape in two angles of 45 and 60 degrees. Several tests were conducted on the models at different speeds of $0.6,0.9$, and $1.2 . \mathrm{m} / \mathrm{s}$. Generated waves in the towing tank are of the regular type with the wavelength changing from $0.6 \mathrm{~L}$ to $1.6 \mathrm{~L}$ by an increment of $0.2 \mathrm{~L} \mathrm{~m}$. The amplitude of the waves was equal to either $35 \mathrm{~mm}$. The heave and pitch response amplitude operator (RAO) versus no dimensional frequencies are presented. The investigations demonstrated that by decreasing inversion angle of bow to 45 degrees motions of the model improved. The results also showed that the interactions between the motions responses leads to the frequent appearance of "Kinks" in a coupled form with the responses of other motions.
\end{abstract}




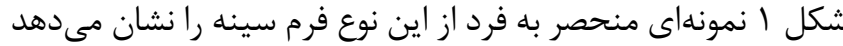

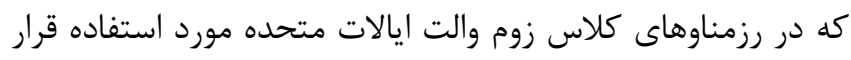

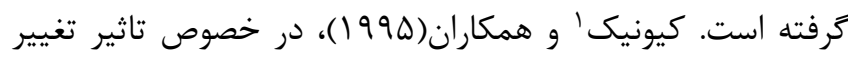
فرم سينه در عملكرد دريامانى يك شناور تك بدنه تحقيقاتى انجام دادند. نتايج نشان داد تغيير در فرم سينه از حالت معمولى به به حالت دان

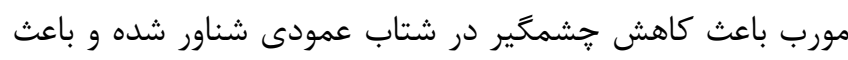

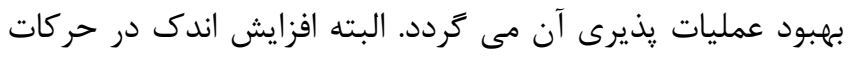

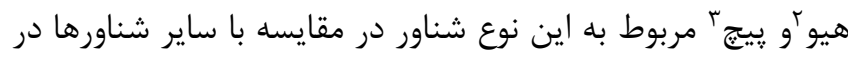

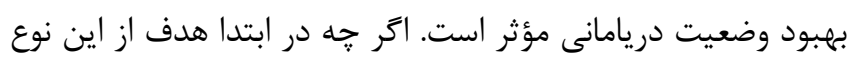

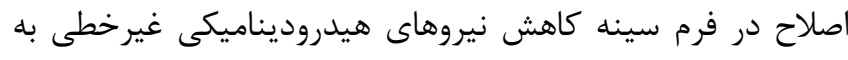

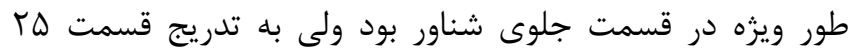

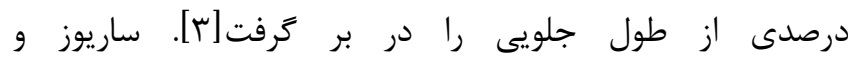

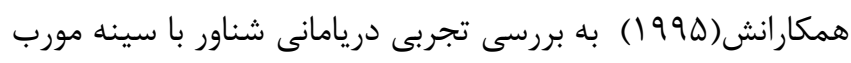

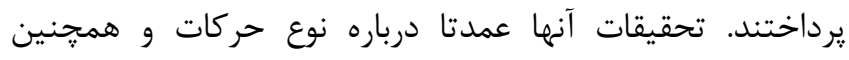

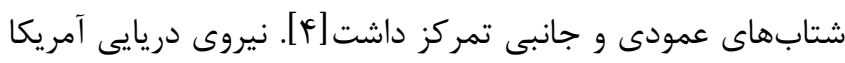

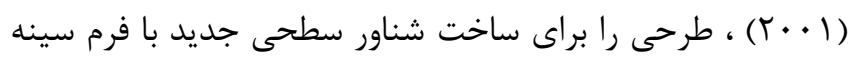

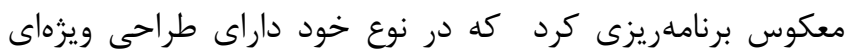

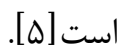

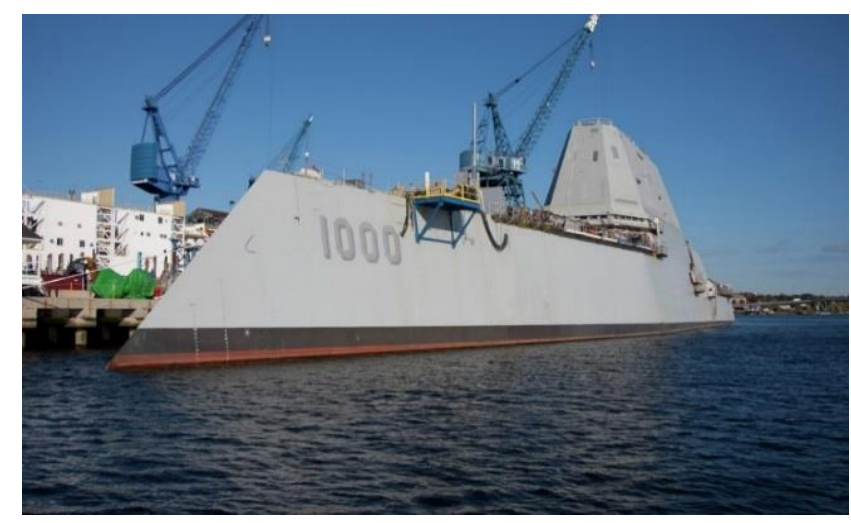

شكل - نمونه از شناور با فرم سينه مورب (رزمناو كلاس زوموالت) [ه]].

با مرور مطالعات انجام شده مشخص است كه در خصوص تاثير فرم سينه معكوس بر روى رفتار هيدروديناميكى شناورها مطالعات اندكى

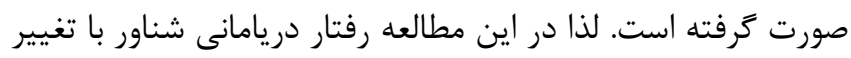

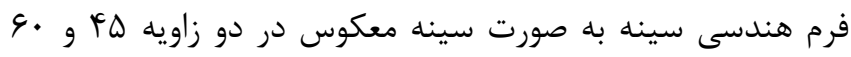

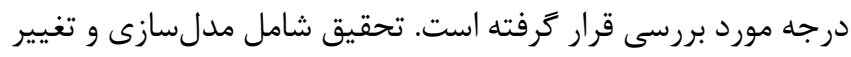
فرم سينه معكوس در يك شناور الكو، ساخت مدل فيزيكى و انجام

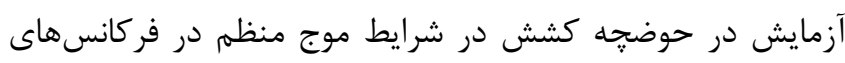
مختلف، سرعتهاى متفاوت در دامنه موج ثابت مىباشد.

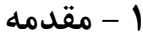

عملكرد دريامانى شناور در يك ناحيه دريايى مشخص از اهميت

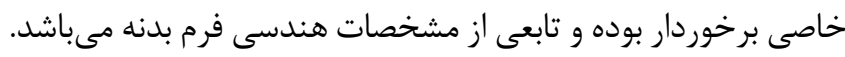
دريامانى قابليت يك شناور جهت داشتن شناورى مطلوب در در شرايط مختلف دريا تعريف مى شود. بهبود بخشيدن به عملكرد دريامانى در

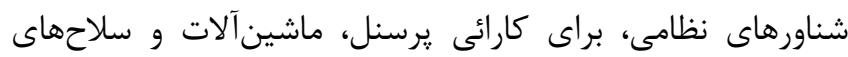

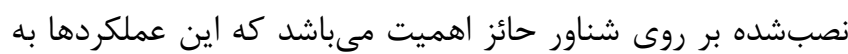

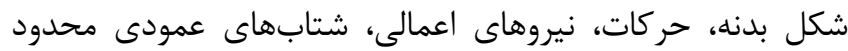

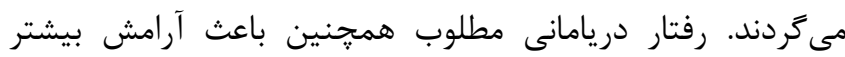

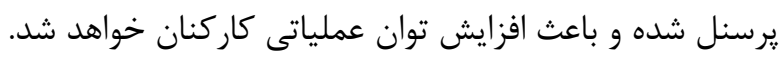

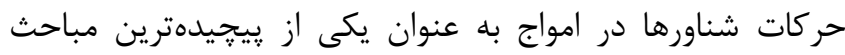

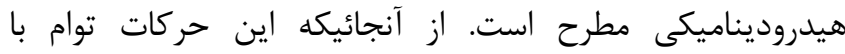

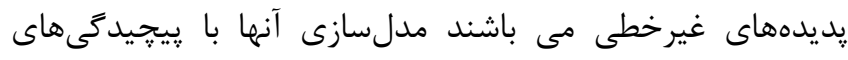

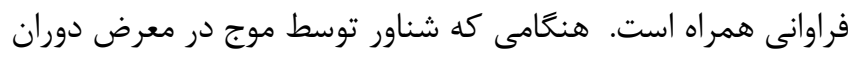
حول محور طولى و عرضى قرار مى گيرد، شتاب حركات هيو، يِيج و و

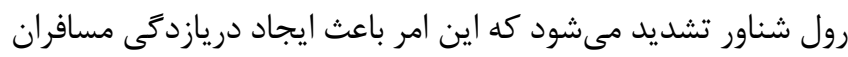

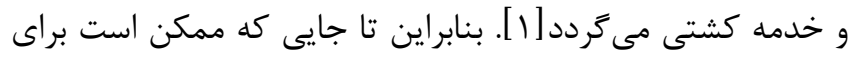

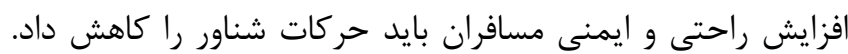

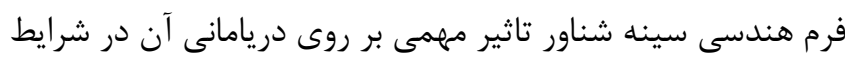

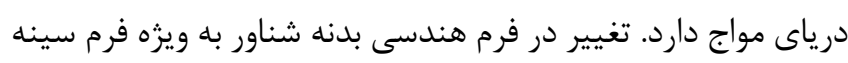

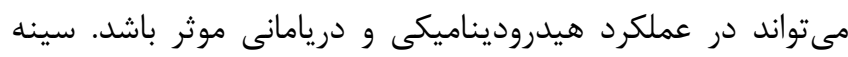

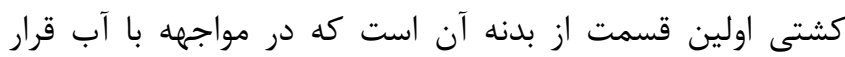

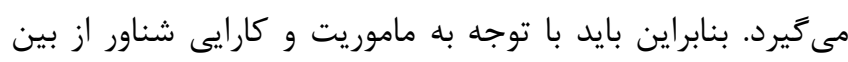

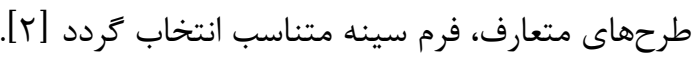

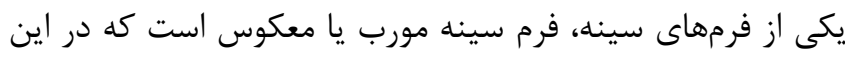

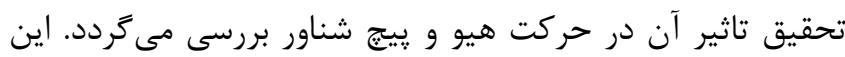

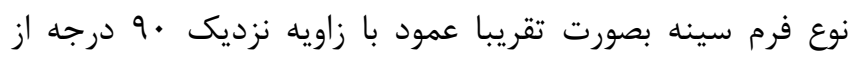

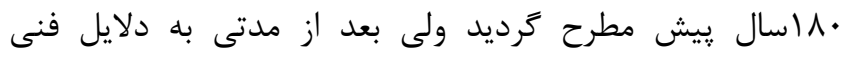

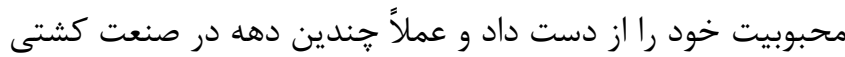

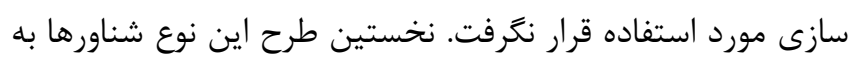

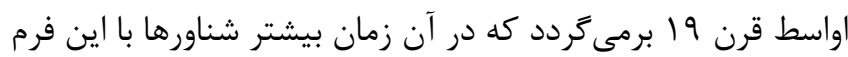

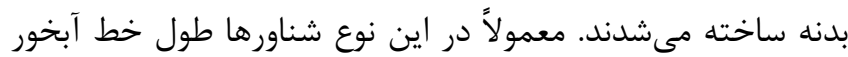

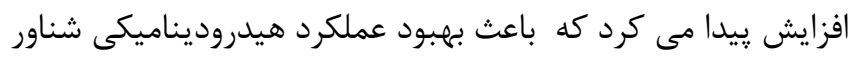

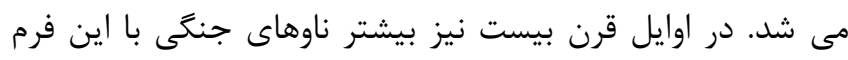
سينه ساخته مىشدند ولى به تدريج به علت افزايش خيسى شنى شناور

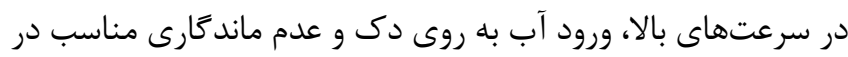

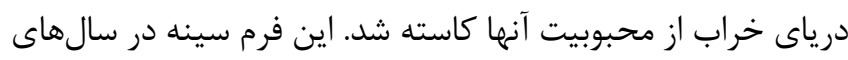
اخير مجددا مورد توجه صنايع كشتىسازى قرار گرفته است. 


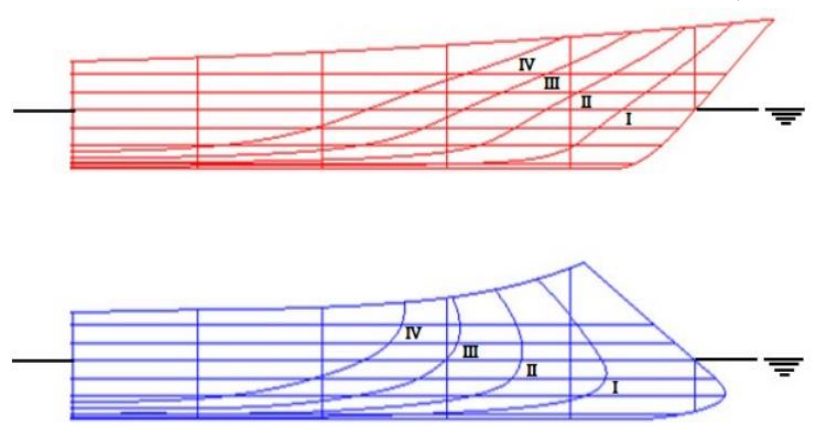

شكل r - طرحى از شناور اصلى با فرم سينه معمولى و تغيير يافته.

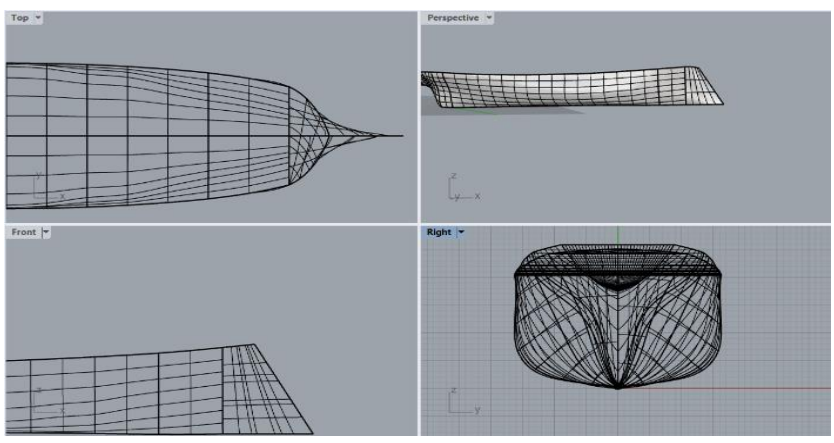

شكل ץ - طرحى از شناور با فرم سينه مورب آماده جهت ساخت.

شكل أ و ه قطعات ساخته شده مدل بوسيله برينتر سه بعدى و آناري

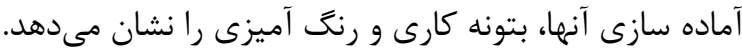

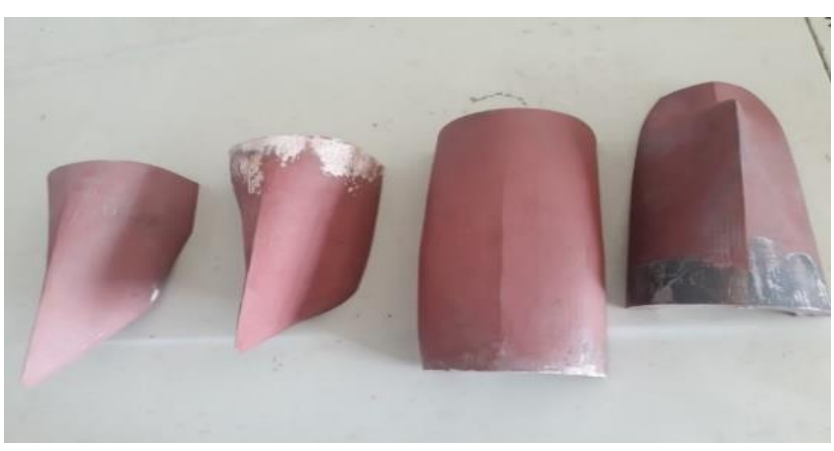

شكل F - آماده سازى قطعات مختلف مدل.

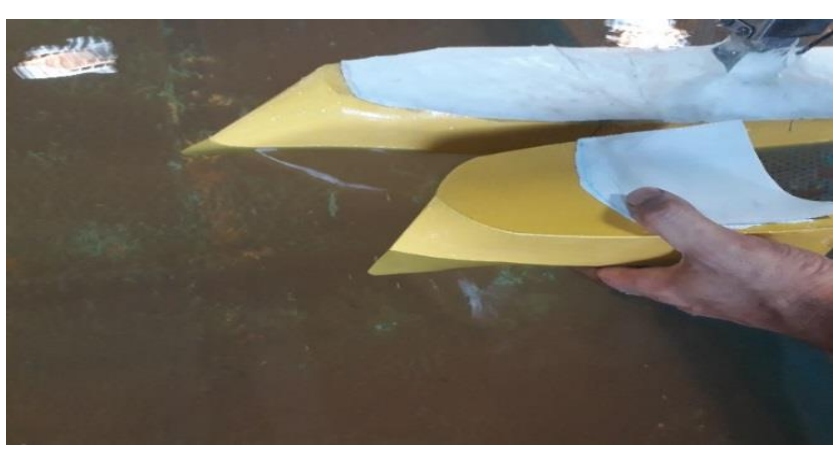

r- تجهيزات آزمايشعاهى و ابزارها

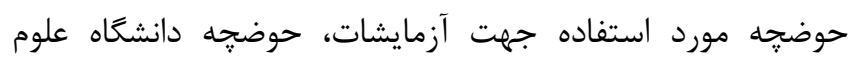

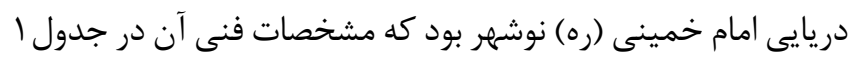

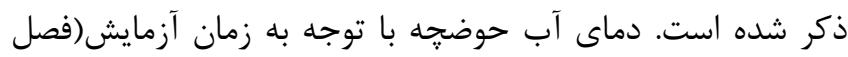

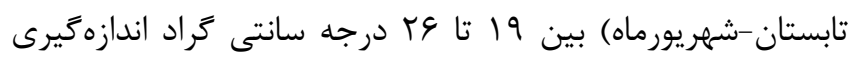

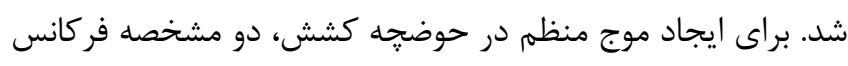

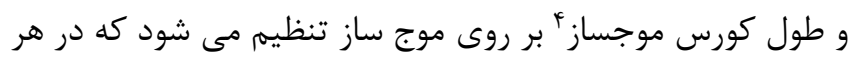

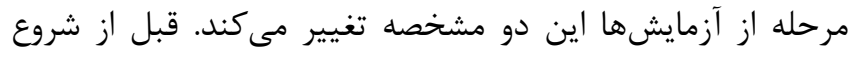

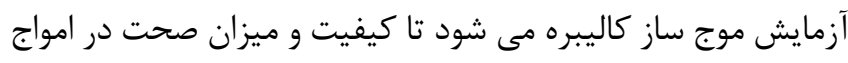

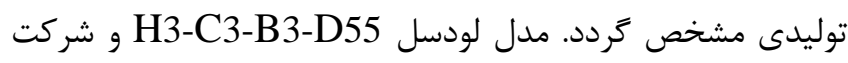

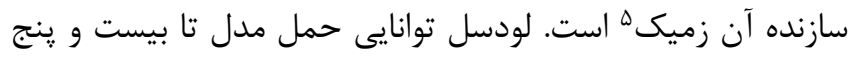

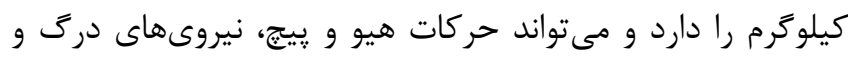
اسوى وَشتاورهاى رول و ياو را اندازهخيرى كند.

جدول 1 - مشخصات حوضجه دانشعاه علوم دريايى امام خمينى (ره).

\begin{tabular}{|c|c|}
\hline مقدار (متر) & مشخصات حوضجه \\
\hline$r v$ & طول \\
\hline r & 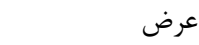 \\
\hline$\cdot / 1$ & عمق \\
\hline$F / \Lambda$ & حداكثر طول موج \\
\hline
\end{tabular}

r- شرح مدل

شناور مدل (NA8-14) يك شناور صيادى است كه به عنوان شناور

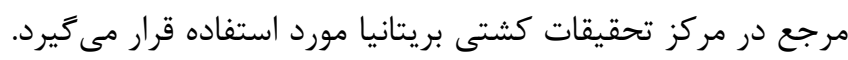

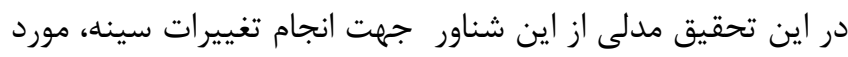
اسكن سه بعدى قرار گرفت و نتيجه آن به نرم افزار راينو منتقل شد.

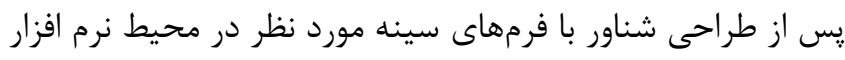

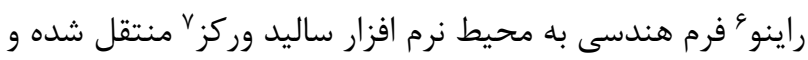
مدل فيزيكى از شناور با ضريب مقياس ا :هN/9 با استفاده از دستخاه

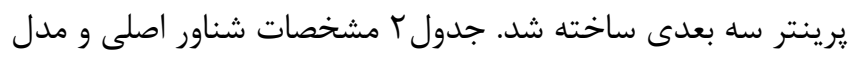

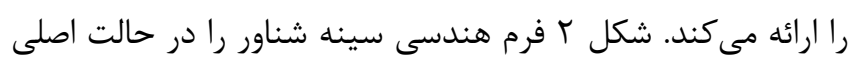

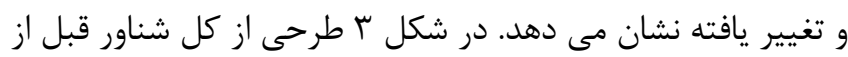
ساخت نمايش داده شده است.

جدول r - مشخصات شناور اصلى و مدل.

\begin{tabular}{|c|c|c|}
\hline مشخصات مدل شناور با سينه مورب & مشخصات شناور اصلى & كميت \\
\hline (سانتيمتر) Vq & (متر) $F \Delta / V$ & طول \\
\hline 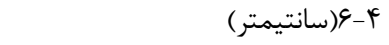 & (متر) & آبخور \\
\hline 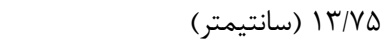 & 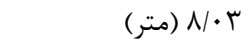 & 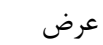 \\
\hline ك & (مته (مترمكعب) & جابجايى \\
\hline
\end{tabular}


جدول ب - ورودى هاى فر كانس و طول مدول مورج

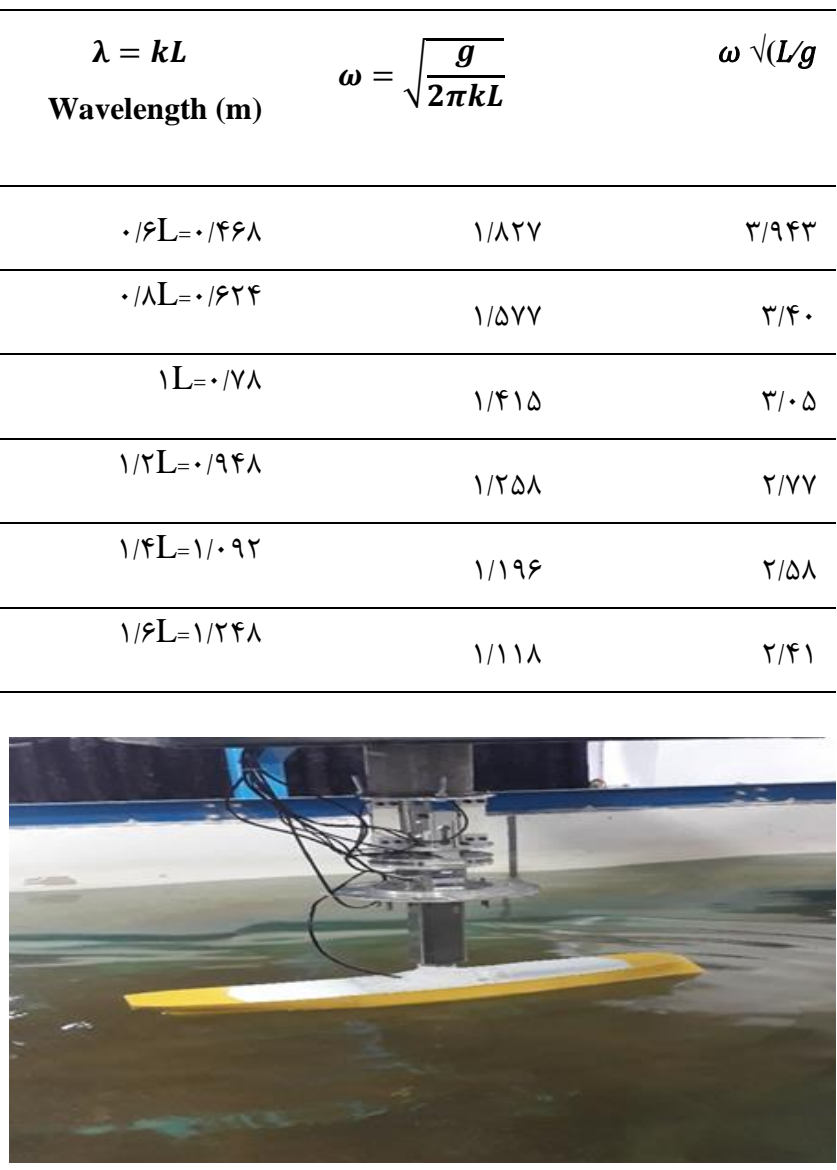

شكل ه - مدل در حال تست آزمايشعاهى در حوضجه كشش.

براى اتصال بازو به مدل ابتدا بايد مركز ثقل مدل تعيين گردد. براى اين كار مدل بر روى تيغه قرار داده شده و يا از دستكاه تعيين مركز

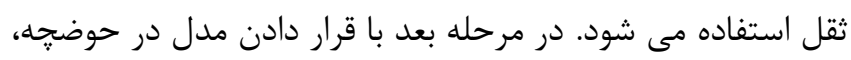

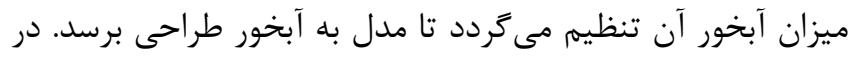

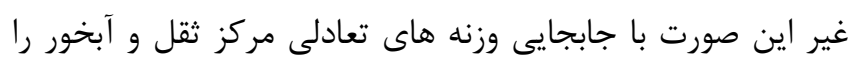

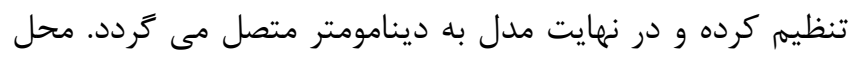
اتصال به صورت فلنج با بيج و مهره آماده مى شود. انجام كاليبراسيون اوليه با دقت زياد و به كمك وزنه در هر مرحله از تست مطابق شكل ع انجام گرديده است.

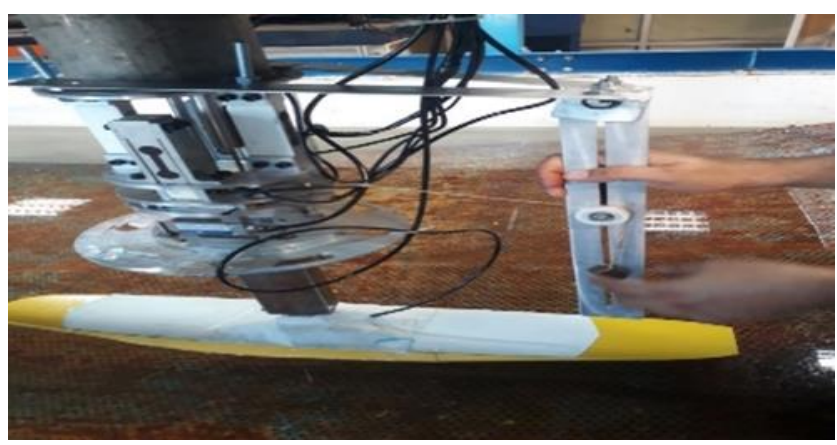

شكل 9 - كاليبراسيون مدل در حوضجه.
F - برنامه آزمايش و محاسبات

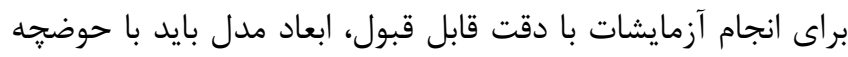

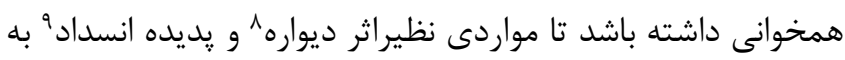

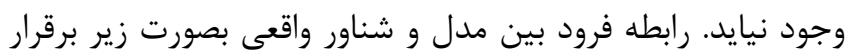

$F_{n_{\text {ship }}}=F_{n_{\text {model }}}$

طول شناور واقعى FD/V متر بوده و طول مدل ساخته شده VIN

$\lambda=\frac{L_{\text {ship }}}{L_{\text {model }}}=\frac{45.7}{0.78}=58.6$

با فرض سرعت اقتصادى هانات براى شناور واقعى ، سرعت مدل طبق روش فرود به صورت زير بدست مى آيد:

$\frac{V_{s}}{\sqrt{L_{s} g}}=\frac{V_{m}}{\sqrt{L_{m} g}} \Rightarrow \frac{V_{s}}{V_{m}}=\sqrt{\frac{L_{s}}{L_{m}}}=\sqrt{\lambda}$

$V_{\text {model }}=\frac{V_{\text {ship }}}{\sqrt{\lambda}}=\frac{15}{\sqrt{58.6}}=1.96 \mathrm{knot}$

بنابراين سرعت مدل جهت تست در حوضجه به صورت زير است:

$V_{\text {model }}=(1.96) \times(0.5144)=1.00 \frac{\mathrm{m}}{\mathrm{s}}$

و با توجه به شاخص قراردادن سرعت بدست آمده، سرعتهاى ييشنهادى براى مدل جهت تست در حوضجه عبارتند از:

$$
u=0.6 \frac{\mathrm{m}}{\mathrm{s}} \quad u=0.9 \frac{\mathrm{m}}{\mathrm{s}} \quad u=1.2 \frac{\mathrm{m}}{\mathrm{s}}
$$

با توجه به منطقه ماموريت شناور و مشخصات امواج خليج فارس و و

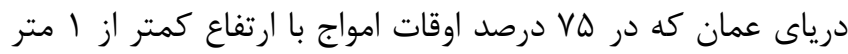

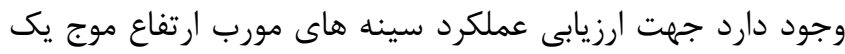
متر درنظر كرفته شد [ب]

$\mathrm{A}=\frac{H}{\lambda}=\frac{1}{58.6}=0.017 \mathrm{~m} \approx 17.00 \mathrm{~mm}$

مدل در سه سرعت مختلف، 9 طول موج و دو دامنه موج براى هر

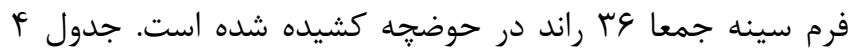
طول موج و فر كانس متناظر را نشان مى دهد. 


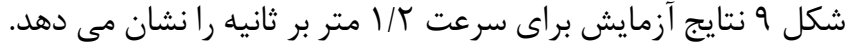

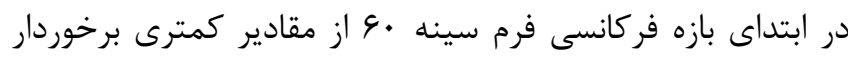

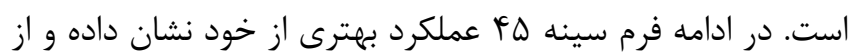

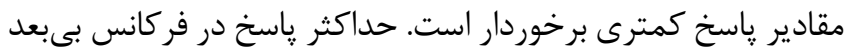

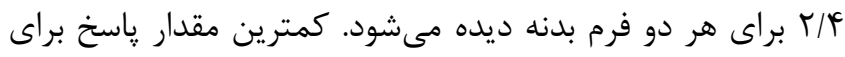

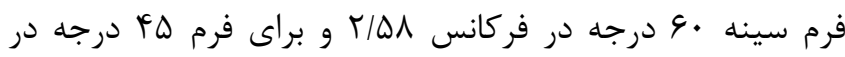

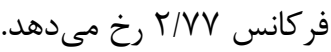

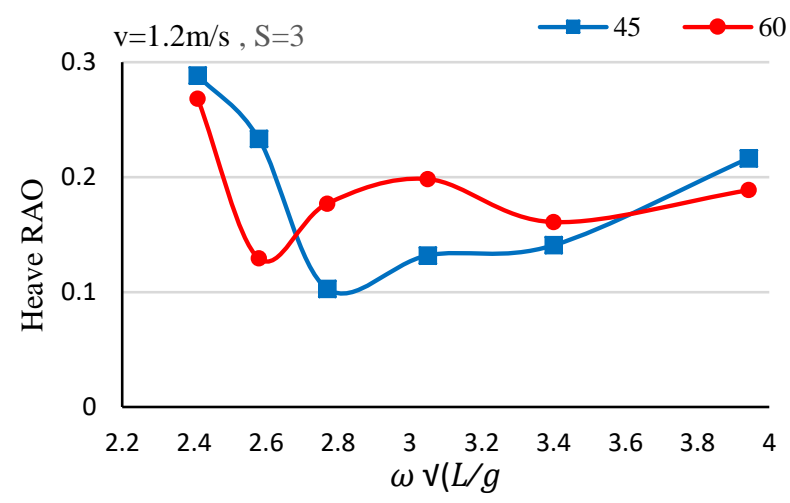

شكل 9- مقايسه رائوى هيو شناور در سرعت ب/1 متر بر ثانيه.

در شكل • ا در سه سرعت مختلف و طول كورس "ا، ميزان رائوى هيو دو فرم سينه را مورد بررسى قرار كرفته است. بيشترين مقادير مربوط

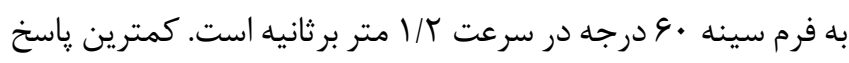

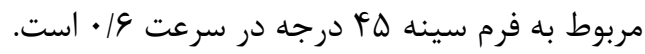

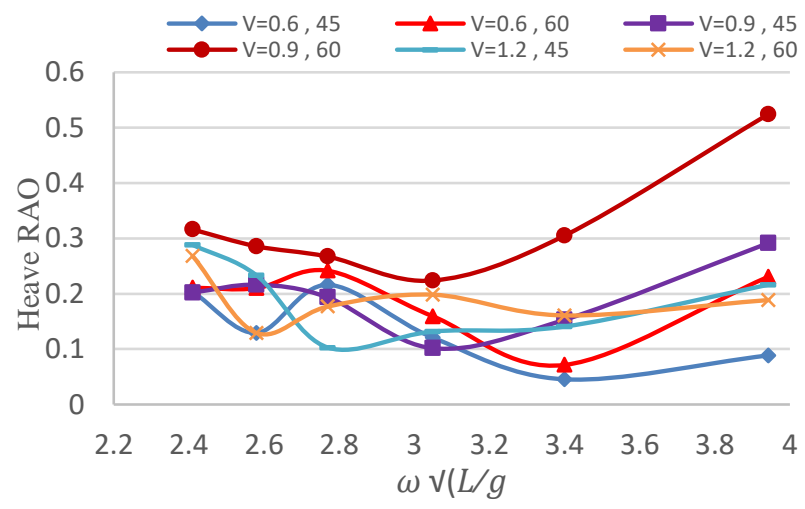

شكل •|- رائوى هيو شناور با دو فرم سينه \&D و •ع درجه در سرعتهاى

مختلف.

در جدول f مقايسه ميانخين تغييرات رائوى حركت هيو فرم سينه مورب •9 درجه با فرم سينه معمولى ارائه شده است. مقادير نشان

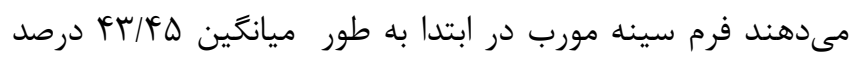

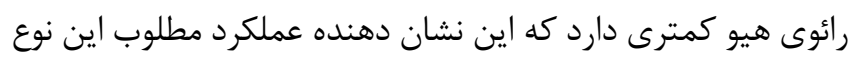

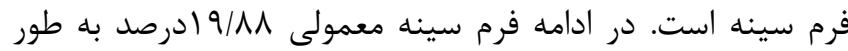
ميانكَين رائوى هيو كمترى داشته است كه نشان دهنده عملكرد
ه- بر رسى نتايج حركت هيو

در شكل هاى V الى • ارائوى هيو مدل براى دو فرم سينه نشان داده

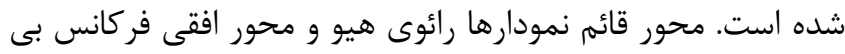

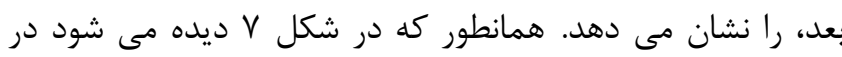

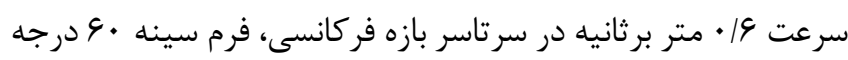

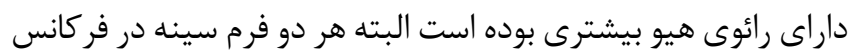

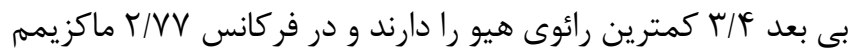

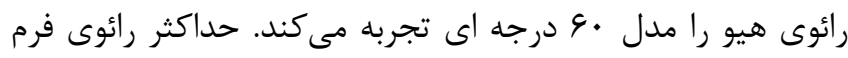

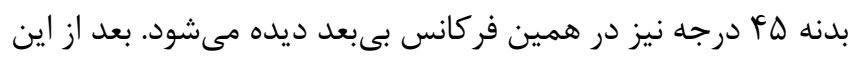

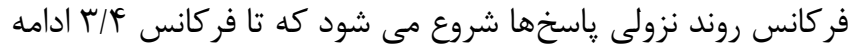

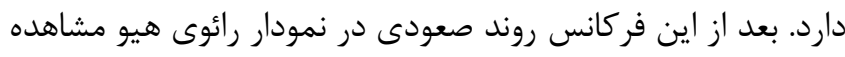

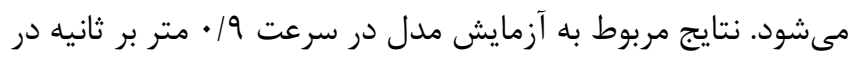
شكل 1 نشان داده شده است. همانطوريكه ديده مىشود در كل كل بازه فركانسى فرم بدنه هأ درجه از مقادير קاسخ كمترى برخوردار است.

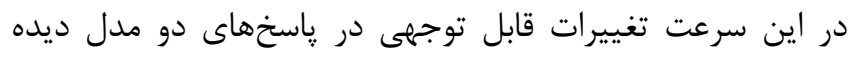

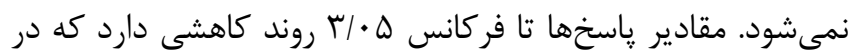
اين فركانس به كمترين مقدار خود رسيده و سيس شروع به إنهايش

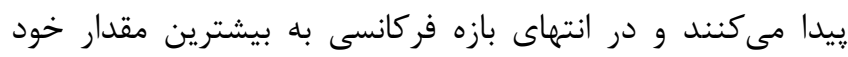

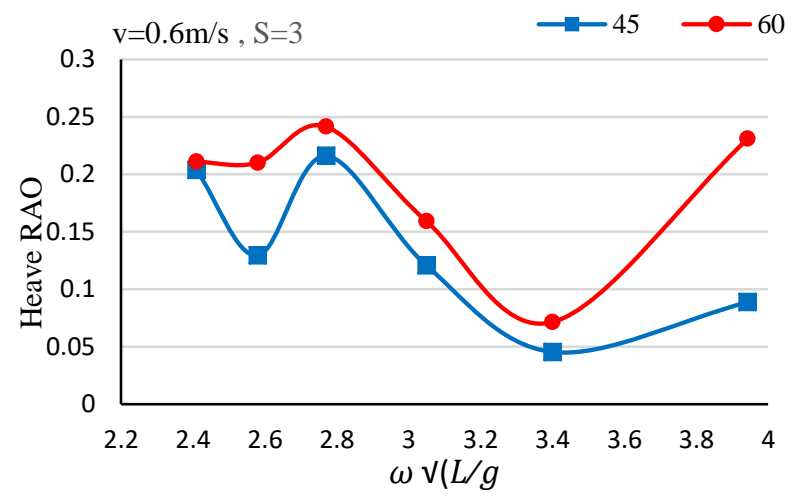

شكل V-مقايسه رائوى هيو شناور در سرعت \&/ متر بر ثانيه.

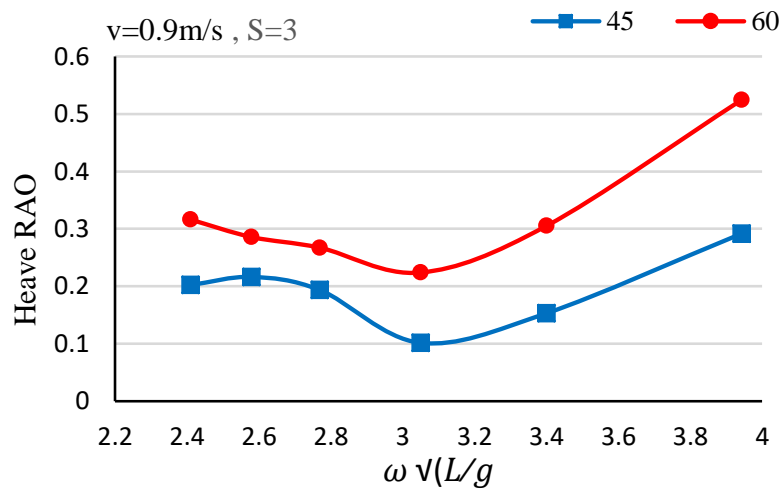

شكل 1- مقايسه رائوى هيو شناور در سرعت 9 / متر بر ثانيه. 


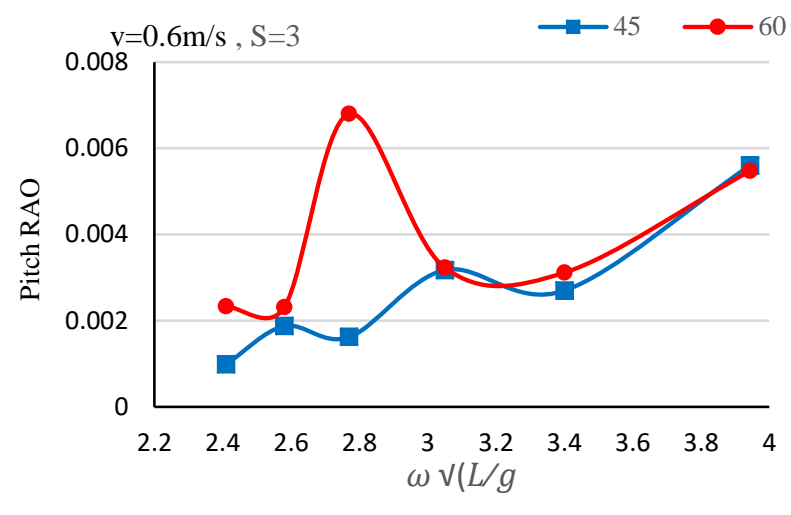

شكل ||-مقايسه رائوى يِيج شناور در سرعت \&/ متر بر ثانيه.

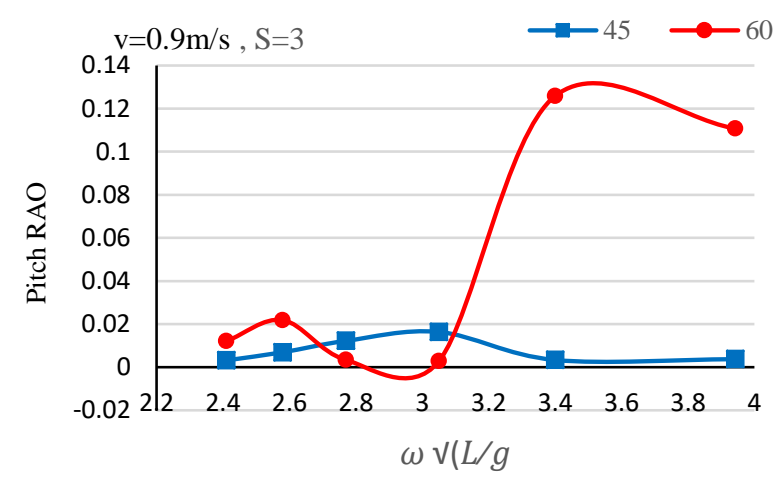

شكل rا-مقايسه رائوى يِيج شناور در سرعت 9/• متر بر ثانيه.

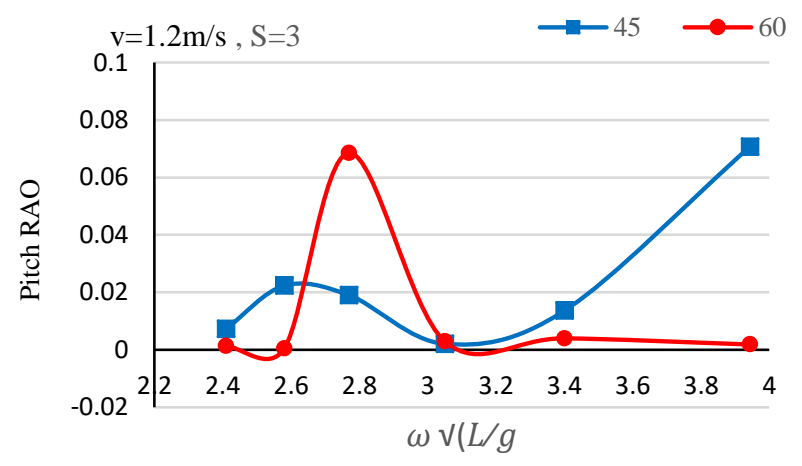

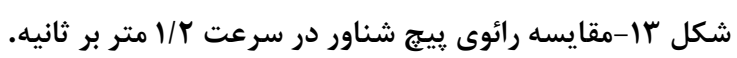

در شكل \& | در سه سرعت مختلف و طول كورس با، ميزان رائوى ييج دو فرم سينه هأو و •ودرجه مورد مقايسه قرار گرفته است. بيشترين

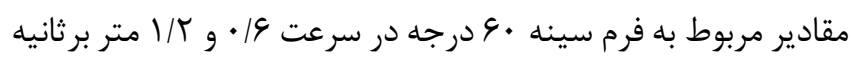

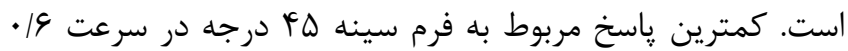

نامطلوب فرم سينه مورب در اين بازه است. در جدول درصد منفى رائوى هيو كمتر فرم سينه مورب را نشان مى دهد.

جدول F-درصد تغييرات هيو براى دو فرم بدنه(معمولى و مورب •9 درجه)

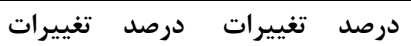

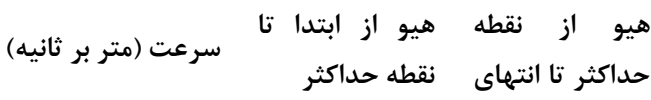

\begin{tabular}{|c|c|c|}
\hline .19 & $-T N / I T$ & $I V / T V$ \\
\hline .19 & $-4 q / r q$ & $r \cdot / 9 r$ \\
\hline $1 / T$ & $-\Delta r / \wedge \Delta$ & TI/FY \\
\hline ميانگين كلى تغيير درصد ها & $-F H / F \Delta$ & $19 / 11$ \\
\hline
\end{tabular}

\section{9- بررسى نتايج حركت پيجج}

در شكلهاى || الى | | ا نتايج رائوى بِيج مدل براى دو فرم سينه در

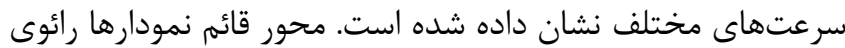
يبيج و محور افقى فر كانس بى بعد، را نشان مى دهد. همانطور كه در شكل || ديده مىشود در سرعت و| • متر برثانيه در بيشتر بازه

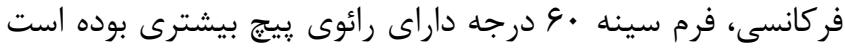

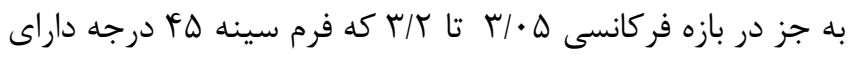

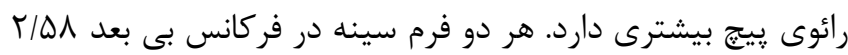

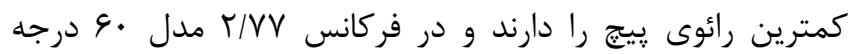

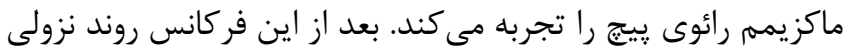

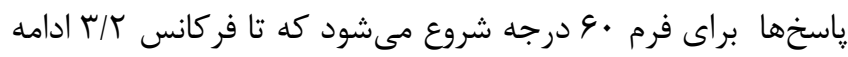

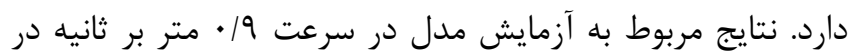

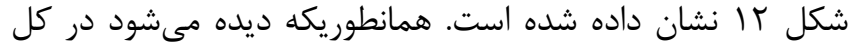

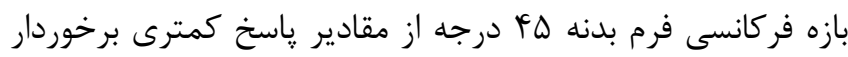

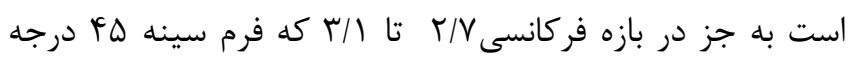
داراى رائوى پييج بيشترى دارد. در اين سرعت تغييرات قابل توجهى دانى

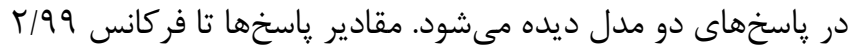

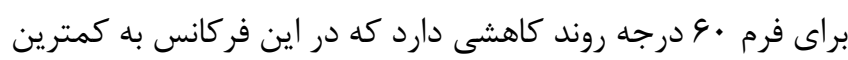

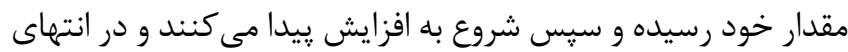
بازه فركانسى به بيشترين مقدار خود معرسند. شكل سار آنتايج

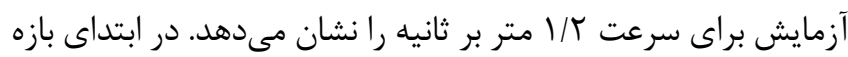

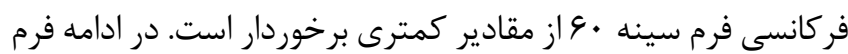

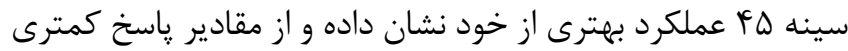
4. برخوردار است و در بازه فركانسى يك سوم انتهايى مجددا فردان

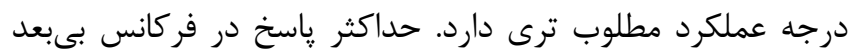

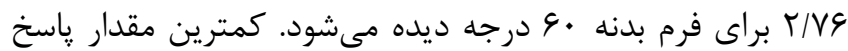

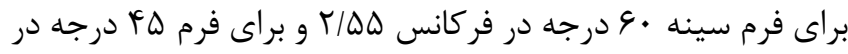

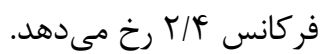


جدول ه-درصد تغييرات بييج براى دو فرم بدنه(معمولى و مورب •9 درجه)

\begin{tabular}{|c|c|c|}
\hline سرعت (متر بر ثانيه) & 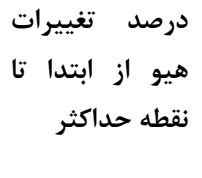 & 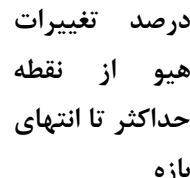 \\
\hline.$/ 7$ & $-r o / \wedge q$ & Ir/ro \\
\hline.$/ 9$ & $r \Lambda / V T$ & $\mid \varepsilon / \varepsilon$. \\
\hline $1 / r$ & $r q / 70$ & $\mid \mathrm{V} / \cdot \mathrm{V}$ \\
\hline ميانكين كلى تغيير درصد ها & $r \varepsilon / V 0$ & $1 \varepsilon / 91$ \\
\hline
\end{tabular}

در جداول 9 و V درصد تغييرات حركات هيو و يبيج در سرعتهاى نداى

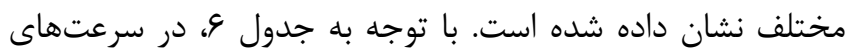

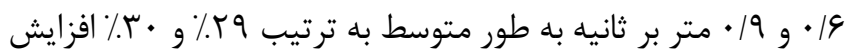

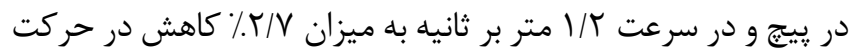

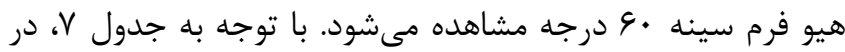

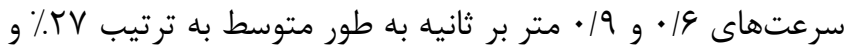

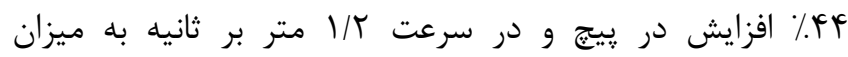

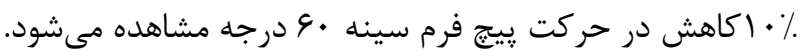

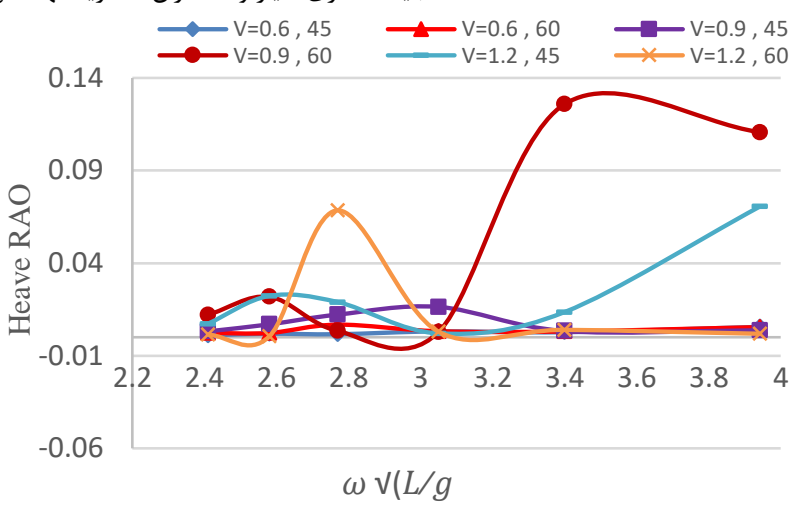

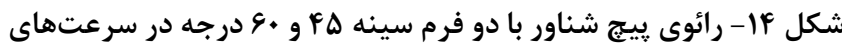
مختلف. در جدول ه مقايسه ميانكين تغييرات رائوى حركت بيج فرم سينه مورب •و درجه با فرم سينه معمولى ارائه شده است. مقادير نشان

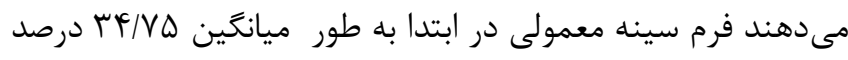
رائوى ييج بيشترى دارد كه اين نشان دهنده عملكرد مطلوب اين نوع

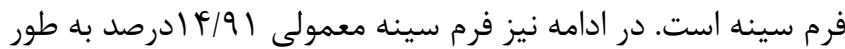
ميانكين رائوى بييج كمترى داشته است كه نشان دهنده عملكرد

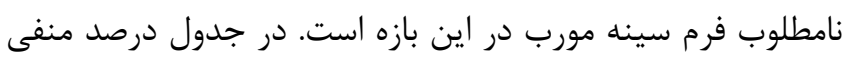
رائوى يِيج كمتر فرم سينه مورب را نشان مىدهد.

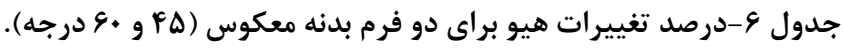

\begin{tabular}{|c|c|c|c|c|c|c|c|c|c|}
\hline \multirow[t]{3}{*}{ فركانس (هرتز) } & \multicolumn{9}{|c|}{ ميزان تغييرات هيو در طول كورس ب سانتى متر } \\
\hline & \multicolumn{4}{|c|}{ 19/ • متر /ثانيه } & \multicolumn{2}{|c|}{ 19/ متتر /ثانيه } & \multicolumn{3}{|c|}{ r/امتر /ثانيه } \\
\hline & 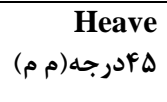 & $\begin{array}{r}\text { Heave } \\
\text { عدرجه(م م). }\end{array}$ & تغرصد & 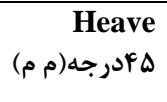 & $\begin{array}{r}\text { Heave } \\
\text { عدرجه م م) }\end{array}$ & تغرصد & 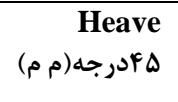 & $\begin{array}{r}\text { Heave } \\
\text { عدرجه م م) . }\end{array}$ & تغييرات \\
\hline $1 / 14$ & $1 / 9 \Delta$ & $\Delta / \cdot \Lambda$ & GT/K & G/FT & $11 / \Delta F$ & $F F / d$ & F/VG & $f / 1 \Delta$ & -14 \\
\hline $1 / 4$ & $1 / 14$ & $1 / \vee 9$ & $r \varepsilon / r$ & $\Delta / \cdot \Lambda$ & V/\&T & $r m / F$ & T/QT & I/DT & $-\Delta \varphi$ \\
\hline $1 / \pi 9$ & $\mathrm{r} / \mathrm{lf}$ & $f / l f$ & rF & r/gF & $11 / \cdot r$ & Ve & t/At & $\Delta / 19$ & $r / \Delta$ \\
\hline $\mid / 41$ & $\Delta / \Lambda F$ & G/DT & $1 \cdot / 4$ & $\Delta / T T$ & $r / V \cdot$ & $-r q / 1$ & $r / V V$ & $F / V V$ & (i) \\
\hline $1 / \Delta \Lambda$ & r/दT & $\Delta / \Lambda \Lambda$ & rN/F & $41 \cdot \Delta$ & $\wedge$ & Tr & $r / Q F$ & r/GT & $-F F / D$ \\
\hline $1 / 1$ & $9 / 11$ & אוא/ & r & 91.9 & $9 / 4 \wedge$ & re & G/Ta & $N / \cdot \Delta$ & $T T / T$ \\
\hline ميانگين درصدها & & & $r q / \cdot 1$ & & & $r \cdot \mid \Lambda F$ & & & $-T / V F$ \\
\hline
\end{tabular}

جدول V-درصد تغييرات ييج براى دو فرم بدنه معكوس (ه و و •ع درجه).

\begin{tabular}{|c|c|c|c|c|c|c|c|c|c|}
\hline \multirow[t]{3}{*}{ فركانس (هرتز) } & \multicolumn{9}{|c|}{ ميزان تغييرات هيو در طول كورس ؟ سانتى متر } \\
\hline & \multicolumn{4}{|c|}{ | ع/ •متر /ثانيه } & \multicolumn{2}{|c|}{ 9/ •متر /ثانيه } & \multicolumn{3}{|c|}{ r/امتر /ثانيه } \\
\hline & 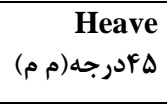 & $\begin{array}{r}\text { Heave } \\
\text { \&درجه(م م). }\end{array}$ & تغرصد & 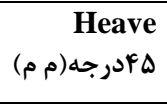 & $\begin{array}{r}\text { Heave } \\
\text { •ودرجه(م م) }\end{array}$ & تغرصد & 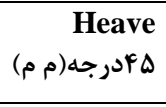 & $\begin{array}{r}\text { Heave } \\
\text { •ودر جه(م م). }\end{array}$ & تغرصير \\
\hline $1 / 14$ & $\cdot|\cdot r|$ & $\cdot / \cdot r \cdot$ & r & $\cdot / 4 t$ & $\cdot \mid 94$ & \& & $\cdot / 49$ & $\cdot / 11$ & $-\mathrm{Vl}$ \\
\hline $1 / 4$ & $\cdot 1 \cdot 19$ & $\cdot / \cdot r t$ & ir & $\cdot / T V$ & $\cdot / 91$ & v. & $\cdot 1 \cdot 91$ & $\cdot 1 \cdot r q$ & V V \\
\hline $1 / \pi 9$ & $\cdot / \cdot r \Lambda$ & $\cdot / \cdot r \Lambda$ & $r / \Delta$ & $\cdot / 1 f$ & $\cdot / \cdot r F$ & $-\wedge \Delta$ & $\cdot 1 \cdot 11$ & $\cdot 1 \cdot r \varepsilon$ & r. \\
\hline $1 / 41$ & $\cdot 1 \cdot 11$ & $\cdot 1 \cdot V F$ & Ve &.$/ 14$ & $\cdot / \cdot r V$ & Ve & $\cdot|r|$ & $\cdot / V \Delta$ & VT \\
\hline $1 / \Delta \Lambda$ & $\cdot / \cdot$ tef & 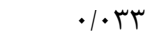 & 11 & $\cdot 1 \cdot 91$ & $\cdot / \pi$ & $\vee \cdot$ & $\cdot / 4 t$ & $\cdot / \cdot \Delta \varphi$ & $-\Lambda r$ \\
\hline $1 / \Lambda$ & $.1 \cdot 14$ & $.1 \cdot \mathrm{FV}$ & $\Delta 9$ & .1 .94 & $\cdot / T F$ & $V \Delta$ & $\cdot / 10$ & $\cdot / \cdot r \Lambda$ & $-\wedge \Delta$ \\
\hline ميانخين درصدها & & & TV & & & fy & & & -1 . \\
\hline
\end{tabular}


[4] Keuning, A., Toxopeus, S. and Pinkster, J., (2012), The Effect of Bow shape On the Seakeeping Performance of a Fast Monohall, www.elsevier. Com. [5] Boulogouris, E. and Papanikolaou, A., (2011), Hull form Optimization of a High Speed Wave Piercing Monohull, www.elsevier. Com.

[6] Chang, ZH. and Sang, H., (2004), investigation of seakeeping of characteristic high speed catamaran in waves, www.elsevier. Com.

[7] Maimeon, A. and Yakoob, O., (2006), seakeeping analyses of a fishing vessel operating in Malaysian water.

[8] Keun, J.A. and van, F., (2011), The comparison of the hydrodynamic behavior of three fast patrol boats with special hull geometries Hydrodynamics, www.elsevier. Com.

[9] Clauss, G.F., (2008), The Taming of the Shrew: Tailoring Freak Wave Sequences for Seakeeping Tests, Journal of Ship Research, Volume 52.

[10]Great Britain Royal navy., (2008), Transactions of the (Royal) Institution of Naval Architects.

[11] Datta, R. and Roudrigez, J., (2011), study of the motion of the fishing vessel by a time domain.

[12] Keuning, J.A., Visch, G.L., Gelling, J. and de Vries L.,(2011), Development of a new SAR boat for the Royal Netherlands Sea Rescue Institution. In Proceedings of the 11th International Conference on Fast Sea Transportation.

[13] Kulzic, J. and Gornics, T., (2014), The analysis of motion dynamic and resistance of multipurpose boats in shallow waters.

[14] Kensett white, J., Brizzolara, S.and Beaver, W. ,(2015), Effect of Inverted bow on the Hydrodynamic Performance of Navy Combatant Hull form.

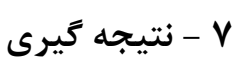

در اين مطالعه تاثير فرم سينه مورب بر روى حركات هيو و رييج يك ديك

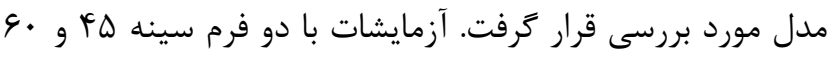
درجه در سه سرعت و شش فر كانس در دامنه موج ها ميليمتر

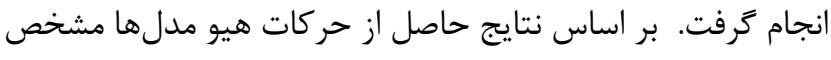
گرديد بيشترين مقادير مربوط به فرم سينه ·و لو درجه در سرعت

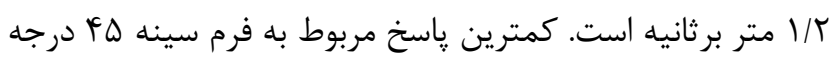

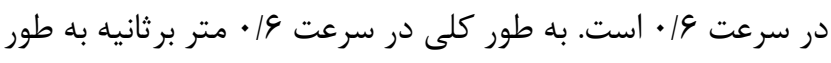

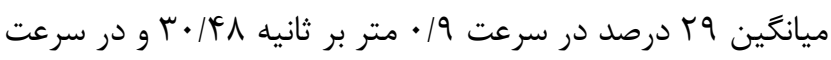

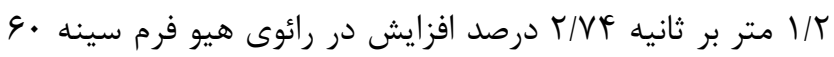
درجه مشاهده شد. در خصوص حركت بييج بيشترين مقادير مربوط به فرم سينه مرجه درجه در سرعت 9/ • و 1/ متر برثانيه است. كمترين ياسخ مربوط

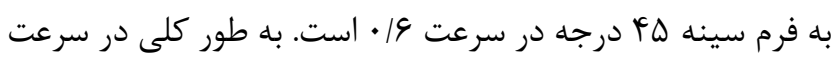

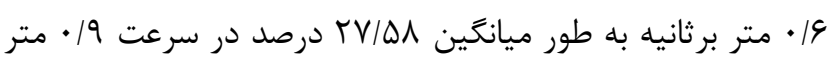

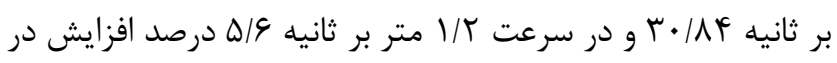
رائوى هيو فرم سينه · ·و درجه مشاهده شد.

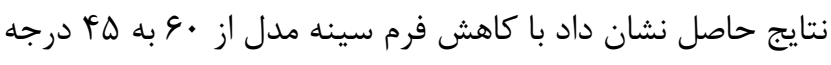

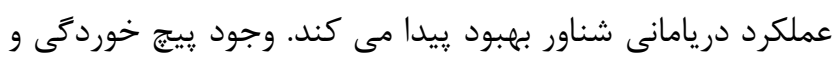

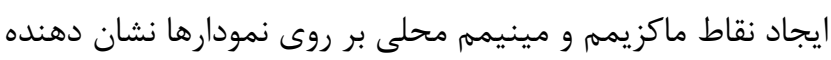

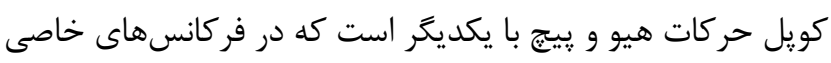
اين يديده رخ مى دهد

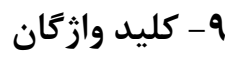

1- Quince

2- Heave motion

3- Pitch motion

4- Stroke

5- ZEMIC

6- Rahino

7- Solid Works

8- Side wall effect

9- Blockage phenomenon

1.

[1] Gammon, M., (2011), Optimization of fishing vessels using a Multi-Objective Genetic Algorithm, Journal of Ocean Engineering, Vol. 38(10), pp. 10541064.

[2] Kukner, A. and Sariöz, K., (1995), High speed hull form optimization for seakeeping

$\therefore$ Adv. Eng. Software, vol.22, pp. 179-189, www.elsevier. Com.

[3]USS Zumvalt Destroyer,(2001), Ship Handling and Stability in High Seas, First Published at Internet, Www.phisical psience.com. 